\title{
REGULARITY OF COMMUTATORS OF MULTILINEAR MAXIMAL OPERATORS WITH LIPSCHITZ SYMBOLS
}

\author{
Ting Chen And Feng LiU*
}

Abstract. We study the regularity properties for commutators of multilinear fractional maximal operators. More precisely, let $m \geqslant 1,0 \leqslant \alpha<m n$ and $\vec{b}=\left(b_{1}, \ldots, b_{m}\right)$ with each $b_{i}$ belonging to the Lipschitz space $\operatorname{Lip}(\mathbb{R})$, we denote by $\left.\vec{b}, \mathfrak{M}_{\alpha}\right]$ (resp., $\mathfrak{M}_{\alpha, \vec{b}}$ ) the commutator of the multilinear fractional maximal operator $\mathfrak{M}_{\alpha}$ with $\vec{b}$ (resp., the multilinear fractional maximal commutators). When $\alpha=0$, we denote $\left[\vec{b}, \mathfrak{M}_{\alpha}\right]=[\vec{b}, \mathfrak{M}]$ and $\mathfrak{M}_{\alpha, \vec{b}}=\mathfrak{M}_{\vec{b}}$. We show that for $0<s<1,1<p_{1}, \ldots, p_{m}, p, q<\infty, 1 / p=1 / p_{1}+\cdots+1 / p_{m}$, both $[\vec{b}, \mathfrak{M}]$ and $\mathfrak{M}_{\vec{b}}$ are bounded and continuous from $W^{s, p_{1}}\left(\mathbb{R}^{n}\right) \times \cdots \times W^{s, p_{m}}\left(\mathbb{R}^{n}\right)$ to $W^{s, p}\left(\mathbb{R}^{n}\right)$, from $F_{s}{ }^{p_{1}, q}\left(\mathbb{R}^{n}\right) \times$ $\cdots \times{F_{s}}^{p_{m}, q}\left(\mathbb{R}^{n}\right)$ to $F_{s}{ }^{p, q}\left(\mathbb{R}^{n}\right)$ and from $B_{s}^{p_{1}, q}\left(\mathbb{R}^{n}\right) \times \cdots \times B_{s}^{p_{m}, q}\left(\mathbb{R}^{n}\right)$ to $B_{s}^{p, q}\left(\mathbb{R}^{n}\right)$. It was also shown that for $0 \leqslant \alpha<m n, 1<p_{1}, \ldots, p_{m}, q<\infty$ and $1 / q=1 / p_{1}+\cdots+1 / p_{m}-\alpha / n$, both $[\vec{b}, \mathfrak{M}]$ and $\mathfrak{M}_{\vec{b}}$ are bounded from $W^{1, p_{1}}\left(\mathbb{R}^{n}\right) \times \cdots \times W^{1, p_{m}}\left(\mathbb{R}^{n}\right)$ to $W^{1, q}\left(\mathbb{R}^{n}\right)$.

Mathematics subject classification (2020): 42B25, 46E35.

Keywords and phrases: Multilinear maximal operator, commutator, boundedness, Sobolev space, TriebelLizorkin space, Besov space.

\section{REFERENCES}

[1] J. M. Aldaz AND J. PÉReZ LÁZARo, Functions of bounded variation, the derivative of the one dimensional maximal function, and applications to inequalities, Trans. Amer. Math. Soc., 359, 5 (2007), 2443-2461.

[2] E. CARNEIRO AND J. MADRID, Derivative bounds for fractional maximal functions, Trans. Amer. Math. Soc., 369, 6 (2017), 4063-4092.

[3] E. Carneiro, J. Madrid And L. B. Pierce, Endpoint Sobolev and BV continuity for maximal operators, J. Funct. Anal., 273, 10 (2017), 3262-3294.

[4] E. Carneiro And D. Moreira, On the regularity of maximal operators, Proc. Amer. Math. Soc., 136, 12 (2008), 4395-4404.

[5] E. CARneiro AND B. F. Svaiter, On the variation of maximal operators of convolution type, J. Funct. Anal., 265, 5 (2013), 837-865.

[6] M. FrAZIER, B. JAWERTH AND G. WeISS, Littlewood-Paley theory and the study of function spaces, CBMS Reg Conf Ser vol 79 Amer Math Soc, Providence, RI, 1991.

[7] D. Gilbarg AND N. S. TRUdinger, Elliptic partial differential equations of second order, 2nd edn., Springer-Verlag, Berlin, 1983.

[8] L. Grafa Kos, Classical and Modern Fourier Analysis, Prentice Hall, Upper Saddle River, NJ, 2003.

[9] P. HaJŁaSZ AND J. MalÝ, On approximate differentiability of the maximal function, Proc. Amer. Math. Soc., 138, 1 (2010), 165-174.

[10] P. HajŁAsZ And J. Onninen, On boundedness of maximal functions in Sobolev spaces, Ann. Acad. Sci. Fenn. Math., 29, (2004), 167-176.

[11] J. Kinnunen, The Hardy-Littlewood maximal function of a Sobolev function, Israel J. Math., 100, (1997), 117-124.

[12] J. Kinnunen And P. LindQvist, The derivative of the maximal function, J. Reine Angew. Math., 503, (1998), 161-167. 
[13] J. Kinnunen And E. SAKsman, Regularity of the fractional maximal function, Bull. London Math. Soc., 35, (2003), 529-535.

[14] S. KORRY, Boundedness of Hardy-Littlewood maximal operator in the framework of Lizorkin-Triebel spaces, Rev. Mat. Complut., 15, 2 (2002), 401-416.

[15] S. KorRy, A class of bounded operators on Sobolev spaces, Arch. Math., 82, 1 (2004), 40-50.

[16] A. K. Lerner, S. Ombrosi, C. Pérez, R. H. Torres and R. Trujillo-González, New maximal functions and multiple weights for the multilinear Calderón-Zygmund theory, Adv. Math., 220, (2009), 1222-1264.

[17] F. LIU, Continuity and approximate differentiability of multisublinear fractional maximal functions, Math. Inequal. Appl., 21, 1 (2018), 25-40.

[18] F. LiU AND G. WANG, Regularity of commutators of maximal operators with Lipschitz symbols, Taiwan. J. Math., 25, 5 (2021), 1007-1039.

[19] F. LiU AND H. WU, On the regularity of the multisublinear maximal functions, Canad. Math. Bull., 58, 4 (2015), 808-817.

[20] F. LiU AND H. WU, On the regularity of maximal operators supported by submanifolds, J. Math. Anal. Appl., 453, (2017), 144-158.

[21] F. LIU AND S. XI, Sobolev regularity for commutators of the fractional maximal functions, Banach J. Math. Anal., 15, 5 (2021), 1-36.

[22] F. LiU, Q. XUE AND K. YABUtA, Regularity and continuity of the multilinear strong maximal operators, J. Math. Pure. Appl., 138, (2020), 204-241.

[23] F. LiU, Q. XUe And P. ZhAng, Regularity and continuity of commutators of the Hardy-Littlewood maximal function, Math. Nachr., 293, 3 (2020), 491-509.

[24] H. Luiro, Continuity of the maixmal operator in Sobolev spaces, Proc. Amer. Math. Soc., 135, 1 (2007), 243-251.

[25] H. LUIRo, On the regularity of the Hardy-Littlewood maximal operator on subdomains of $\mathbb{R}^{n}$, Proc. Edinburgh Math. Soc., (2) 53, 1 (2010), 211-237.

[26] C. PÉREZ AND R. H. TORRES, Sharp maximal function estimates for multilinear singular integrals, Contemp. Math., 320, (2003), 323-331.

[27] H. TRIeBel, Theory of Function Spaces, Monogr Math vol 78, Birkhäser Verlag, Basel, 1983.

[28] K. YABUTA, Triebel-Lizorkin space boundedness of Marcinkiewicz integrals associated to surfaces, Appl. Math. J. Chinese Univ. Ser. B., 30, 4 (2015), 418-446.

[29] P. ZHANG, Multiple weighted estimates for commutators of multilinear maximal function, Acta Math. Sin. Engl. Ser., 31, 6 (2015), 973-994. 